\title{
SUBJECTS INDEX
}

A

Aero-gel

Acidity

Acid grade fluorite

Amines to Imines

Aldimines

Alumina-Supported

Autothermal

B

Basicity

Bipyridine

C

Caprolactone

carbonate ion

calcium oxalate

Cellulose Fiber

Cerium oxide

Ceria-Based Mixed Oxide

Ceria-titania

Copolymerization

Crystalline phase

Cryolite

D

De-oxygenation

Dry reforming

$\mathbf{E}$

Electrolysis

Epichlorohydrin

F

Freeze Drying

Fluorite Crystal

Fuel Cell

G

Green Catalyst

Gypsum

H

Hydro-gel

Hydrogen production

J

JCPDS
$\mathbf{K}$

Ketimines

79

M

Maghnite 43

Montmorillonites

43

N

Nano-Gold

O

Oxidative Dehydrogenation $\quad 79$

49,51

73

49,51

79

79

81,82

43,44

61

72

R

Rice Husk

$1,2,42,19$

59

60

29

43

18

71,72

$\mathbf{P}$

Permeability coefficient $\quad 52,53$

Phosphoric Acid 71

Photocatalyst $\quad 30$

Polymer membrane $\quad 49$

$\mathbf{S}$

Silica Gel $\quad 1,71,72$

Steam reforming $\quad 29,30$

Supercritical 14

Suprnatant $\quad 72,73$

$\mathbf{T}$

Thermochemical 29

W

Water gas shift $\quad 33$

Weight Hourly Space Velocity 36

$\mathbf{X}$

Xero-gel 8 